\title{
JAVAANSE OUDHEDEN IN DEN HAAG: HAAGS-INDISCH ERFGOED ROND 1900
}

Hoewel in de Hofstad geen Kamer van de Vereenigde Oostindische Compagnie gevestigd was, nam Den Haag al in de $17^{\mathfrak{e}}$ eeuw deel aan het internationale verkeer met Azië. Bewindhebbers van de VOC, zoals Anthony Patras, woonden aan het Lange Voorhout. De Haagse paleizen van het koningshuis werden verrijkt met oosterse decoraties en geschenken van bezoekende vorsten en hoogwaardigheidsbekleders uit de koloniën. De voortdurende commerciële en culturele uitwisseling met Azië heeft haar sporen achtergelaten in het stadsbeeld. Vooral de band met voormalig Nederlands-Indië, de 'Gordel van Smaragd', is nog te herkennen in de naamgeving van wijken, straten en gebouwen, in geveldecoraties en interieurs. ${ }^{1}$

In mei 2013 presenteerde de afdeling Monumentenzorg van de Gemeente Den Haag de resultaten van het erfgoedproject Sporen van Smaragd. ${ }^{2}$ Dit was gericht op het inventariseren van Haags-Indisch erfgoed (1853-1945), van woonhuizen van repatrianten en de eerste toko's tot kantoren van cultuurmaatschappijen en bouwwerken van architecten met een Indische achtergrond. Het project maakte duidelijk hoezeer architectuur een uiting van identiteit en ambitie is. Overheidsgebouwen weerspiegelden het uitgeoefende gezag over de kolonie door opname van personificaties van Nederlands-Indië in interieurdecoraties, terwijl kantoorpanden door het aanbrengen van het stadswapen van Batavia op de gevel lieten zien dat zij in Holland én Indië voor de consument klaarstonden. De naamgeving en geveldecoraties van luxe repatriantenvilla's herinnerden bewoners aan het mooie, achtergelaten land, terwijl in onopvallende woonhuizen juist culturele uitwisseling in de praktijk werd gebracht door kunstenaars, auteurs en musici. Dit artikel belicht twee voorbeelden die geïnspireerd zijn op Javaanse oudheden.

\section{Raamweg 16}

Rond 1905 werd aan de Raamweg een reeks particuliere huizen gebouwd. Op nummer 16 is in een klein vertrek, rechts van de ingang, een bijzonder glas-in-loodraam bewaard gebleven (afb. 1). Het bestaat uit drie gebrandschilderde panelen. ${ }^{3}$ In het midden is, conform het opschrift onderaan het paneel, de Prajnaparamita van Singosari weergegeven. De boeddhistische godin van de hoogste wijsheid is hier afgebeeld op een lotustroon met haar handen in de dharmacakramudra, de handhouding van het in beweging zetten van het rad van de boeddhistische leer. De boog rond haar hoofd wordt gevormd door twee makara's, mythische zeedieren met een olifantenslurf. Deze voorstelling is ontleend aan een $13^{\mathrm{e}}$-eeuwse sculptuur die in Singosari (Oost-Java) werd gevonden (afb. 2), maar al vroeg naar het

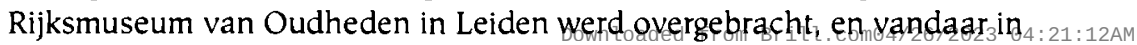
1903 verhuisde naar het Rijksmuseum Volkenkunde. ${ }^{4}$ Op de zijpanelen vaan ${ }^{\text {access }}$ 

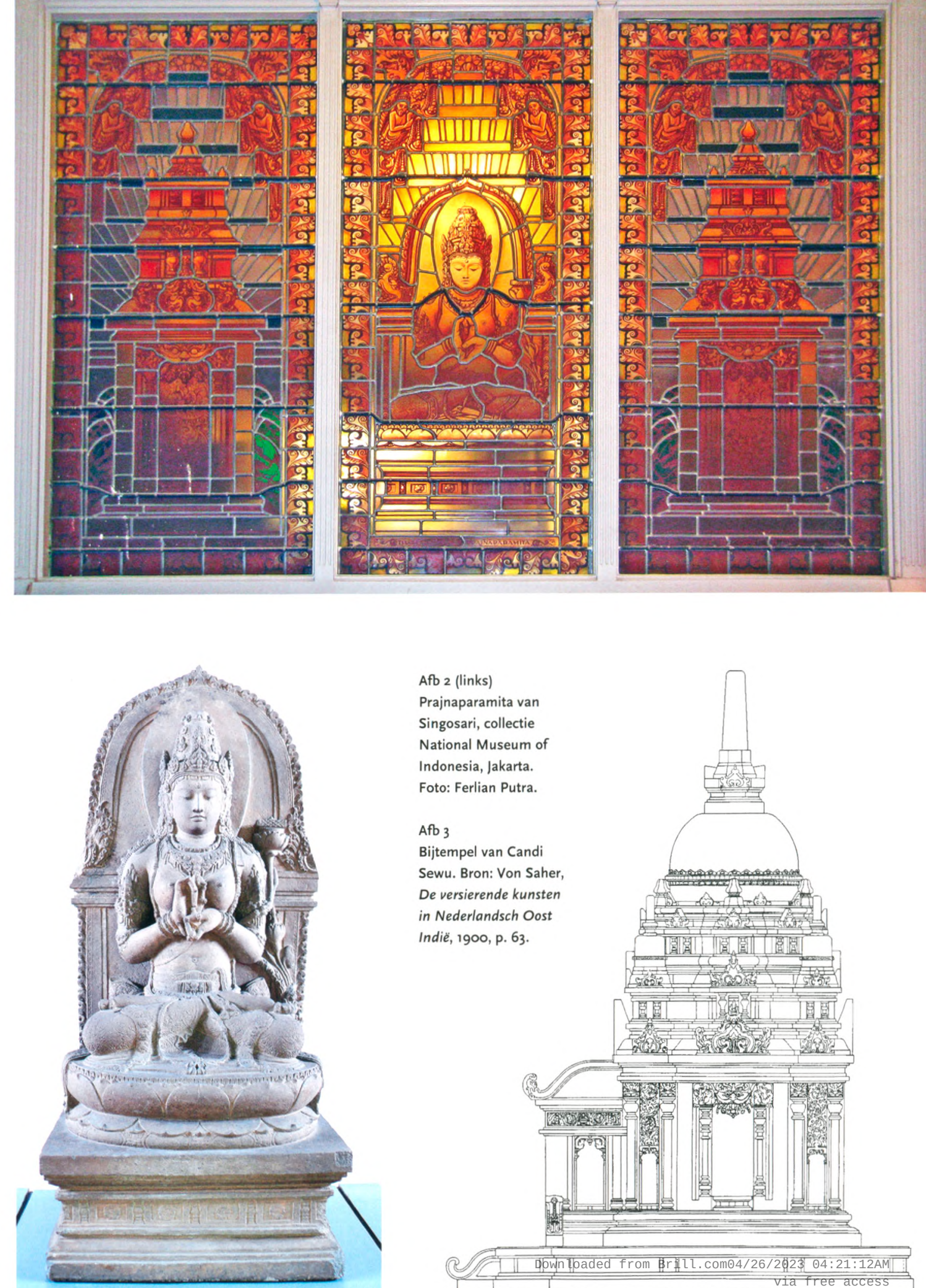

Afb 2 (links)

Prajnaparamita van

Singosari, collectie

National Museum of

Indonesia, Jakarta.

Foto: Ferlian Putra.

Afb 3

Bijtempel van Candi

Sewu. Bron: Von Saher,

De versierende kunsten

in Nederlandsch Oost

Indië, 1900, p. 63.
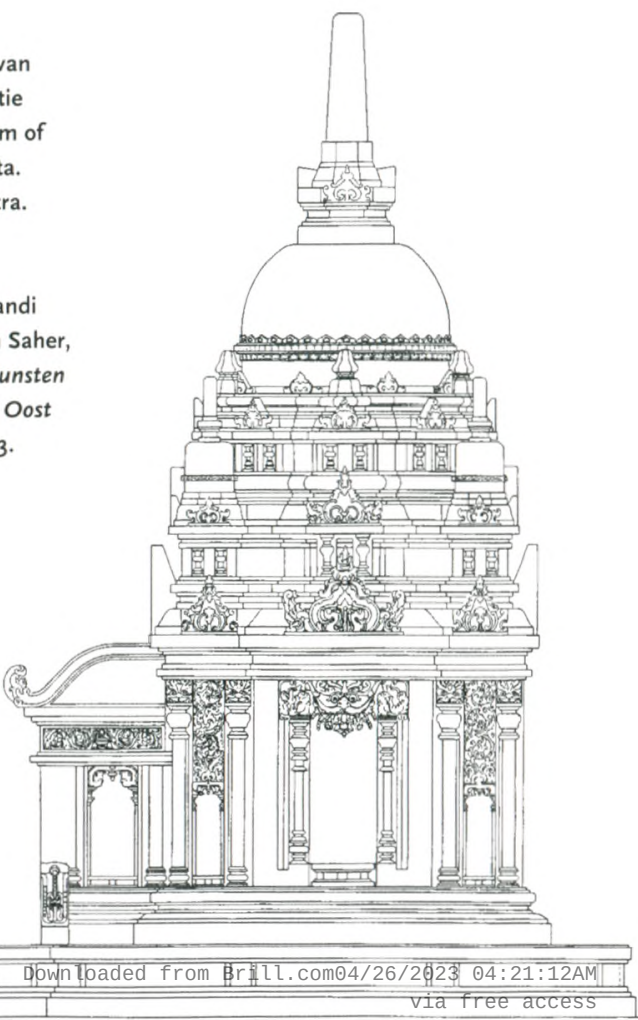
Afb , (links) Raamweg 16. Foto Kroon \& Wagtberg Hansen, Den Haag.

Afb 4

Zienermotief bovenaan de bovenste poorten van Borobudur. Foto's: Marijke Klokke. het raam is tempelarchitectuur met een monsterkop (kala) weergegeven. Het betreft een vrij nauwkeurige weergave van het uitspringende middengedeelte van een van de bijtempels van het Sewu tempelcomplex (MiddenJava, $8^{\mathrm{e}}$ eeuw, zie afb. 3). De Bodhisattva onder het kala-motief is vervangen door een arabesk motief, zoals te vinden op de muurdelen ter weerszijden van het middengedeelte van die bijtempel. De drie Haagse raampanelen zijn bovenaan voorzien van een ronde boog waarin bebaarde figuren te midden van guirlandes zijn afgebeeld. Ook hier is een duidelijke inspiratiebron: de bovenste vier poorten van de Borobudur (Midden-Java, $8^{\mathrm{e}}$ eeuw) hebben een zelfde versiering met wijze zienerfiguren ( $r s i)$ te midden van guirlandes ( $a f b .4$ ).

\section{Binnenhof 7}

In 1916-1917 werd het Departement van Koloniën uitgebreid met een nieuwe vleugel. Deze kreeg een overhuifde entree aan Binnenhof 7. In de gevel zijn nu nog twee gevelreliëfs naar ontwerp van beeldhouwer Johannes P.H. (Joop) van Lunteren (1882-1958) te zien. Het rechter reliëf stelt de aankomst van de eerste Hollanders in Indië voor en verwijst naar het drijven van handel. De flankerende taferelen en de geornamenteerde lijst rondom (afb. 5) zijn geïnspireerd op een motief dat karakteristiek is voor het Prambanan tempelcomplex (Midden-Java, $9^{c}$ eeuw). De basis van de zes grootste tempels van dat complex is voorzien van een zich herhalend motief dat bestaat uit een nis (met een leeuwenfiguur) geflankeerd door twee reliëfpanelen. De reliëfpanelen tonen hemelbomen met daaronder verschillende dieren, ook mythische mensvogels (kinnara's), zoals op afbeelding 6 . De bomen zijn in de top
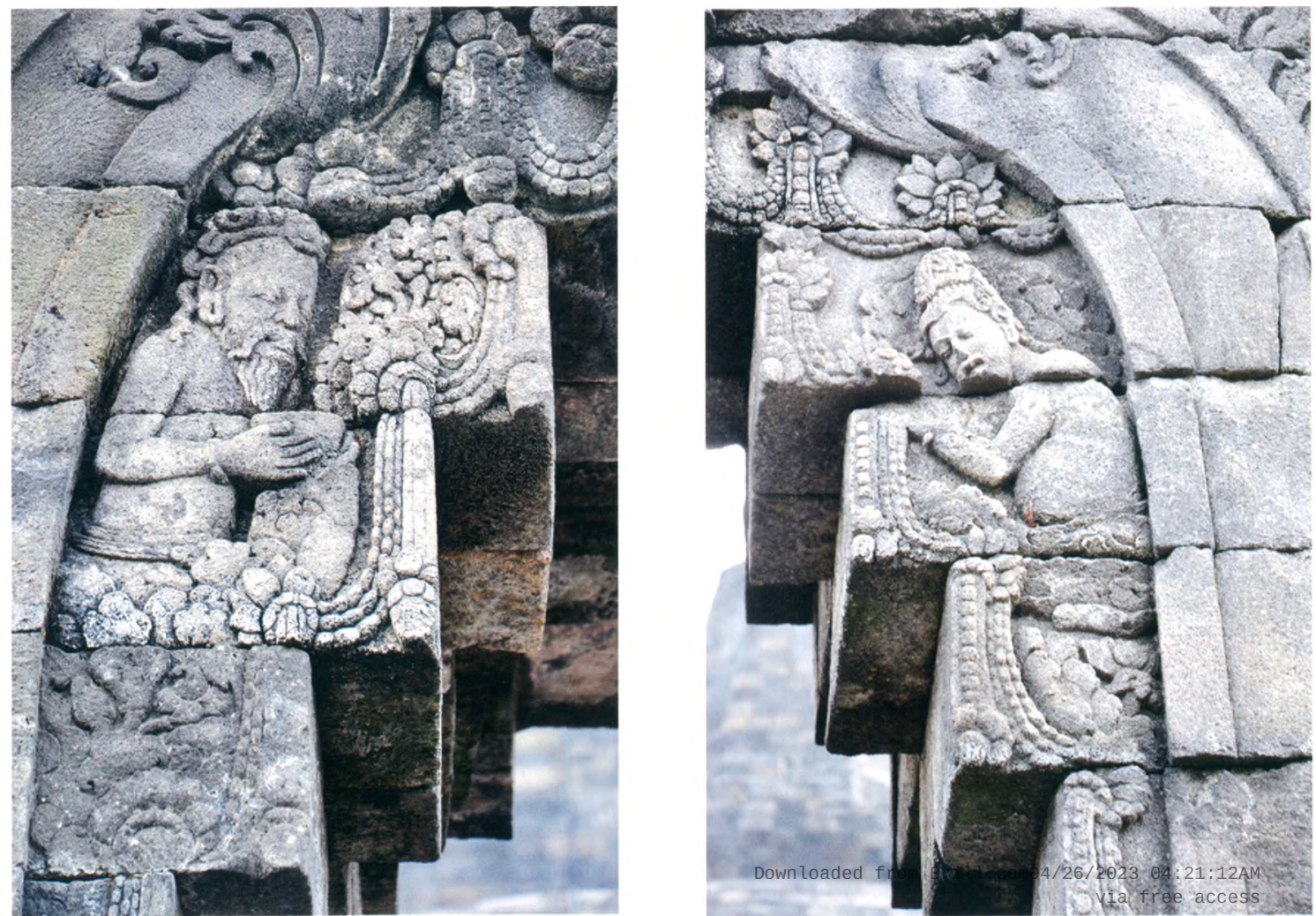

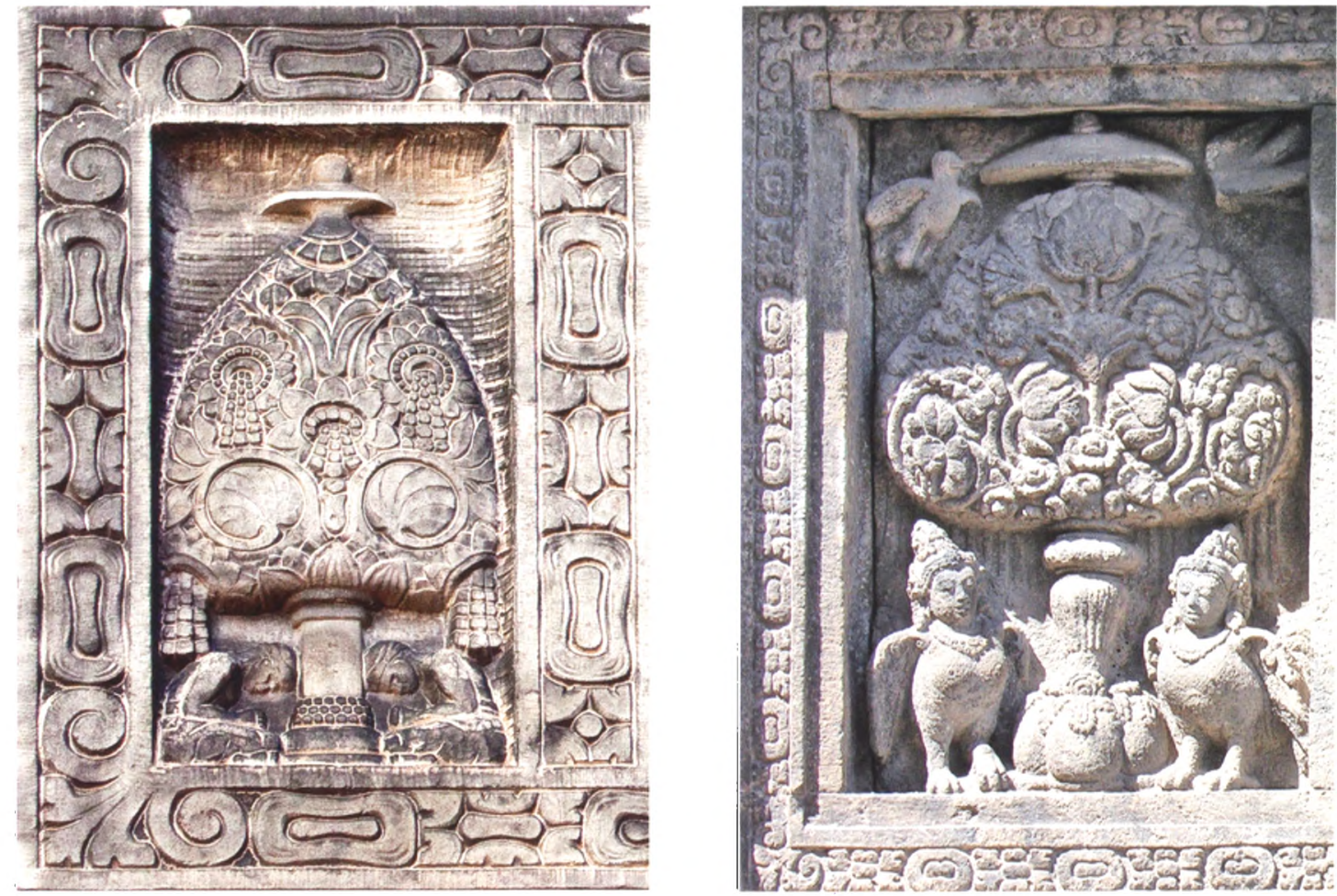

\section{Afb 5 (links) \\ Binnenhof 7, \\ Foto: Dick Valentijn, Monumentenzorg Den Haag.}

Afb 6 Prambanan-motief, Candi Siva. Foto: Marijke Klokke. voorzien van een parasol als teken van heiligheid. De boompanelen worden omlijst door een rand van bloemetjes en ovaaltjes. De Haagse rand, die hier duidelijk op is geïnspireerd, laat zes-bladige bloemetjes zien, die we alleen vinden op de hoofdtempel (Candi Siva) van het Prambanan complex. Van Lunteren nam deze rand, uitvergroot en in zijn eigen stijl, nauwgezet over. De dieren aan de voet van de boom verving hij door twee figuren (Javanen) in kleermakerszit met voorover gebogen hoofden alsof ze aan het werk zijn. In het linker gevelreliëf was de naam van het ministerie aangebracht (later verwijderd). De flankerende panelen, met een zelfde rand, tonen een Boeddhabeeld in een nis die door een monsterkop (kala) wordt bekroond. De Boeddha lijkt de hand in de bhumisparsamudra (aanraken van de aarde) op zijn knie te hebben geplaatst. Deze afbeelding zou gemaakt kunnen zijn naar het voorbeeld van een Boeddha-nis op Borobudur.

\section{Inspiratiebron}

Veel kennis was er in Nederland aan het begin van de $20^{\mathrm{e}}$ eeuw nog niet van de Javaanse kunst. De Wereldtentoonstelling van 1900 in Parijs speelde een belangrijke rol in het verspreiden van de kennis en vergroten van de status ervan. ${ }^{5}$ Op die tentoonstelling waren kopieën te zien, in gips nagemaakt, van Midden-Javaanse tempels, tempelornamenten en beelden. E.A. von Saher, directeur van de School voor Kunstnijverheid te Haarlem, was daartoe aangesteld als 'architect voor de Hindoe-monumenten der Nederlandsch-Indische Afdeeling'. Als zodanig reisde hij in 1898 naar Java om mallen van MiddenJavaanse beelden en tempelornamenten te maken, waarmee veryolgens in Haarlem gipsafgietsels werden gemaakt. 
Zoals we kunnen lezen in het Verslag van de Centrale Commissie voor die tentoonstelling, bleek deze verzameling afgietsels van 'zoo groote artistieke en oudheidkundige waarde te zijn' dat van een deel daarvan in 1899 in het Koloniaal Museum in Haarlem een tentoonstelling werd georganiseerd.

Deze trok 'de aandacht van de geheele artistieke en bouwkundige wereld en van het groote publiek in niet geringe mate' en kreeg ook belangstelling van de koninklijke familie. ${ }^{6}$ In 1900, ter gelegenheid van de Wereldtentoonstelling, kwam ook een groot formaat boek uit, van de hand van Von Saher, waarin foto's van enige van die gipsafgietsels. Het zijn prachtige afbeeldingen, in 20 platen, zonder de mosgroei en verwering van de originelen.

Het zou heel goed kunnen dat voor het raam aan de Raamweg, dat niet lang erna werd gemaakt, uit dit boek is geput. We vinden er alle onderdelen: de Prajnaparamita van Singosari (pl. XX), het bijtempeltje van Candi Sewu (het geheel op p. 65, een tekening op p. 63 en een gedeelte in pl. IX), arabesk motieven (pl. XVIII), en de Borobudur poort met zienerfiguren (pl. XVII). Maar ook de afgietsels zelf kunnen zijn gebruikt. Op p. 94 van Von Saher's boek is een foto van een van de kamers van de tentoonstelling in Haarlem, volgestouwd met afgietsels van Javaanse tempelreliëfs, beelden en complete tempelmuren. In het hierboven genoemde Verslag lezen we dat afgietsels ook naderhand nog bijgemaakt werden en aan verschillende musea verkocht. Ze werden nog lang tentoongesteld, bijvoorbeeld op een tentoonstelling over het hindoeïsme van Java en Bali in het Stedelijk Museum in $1915^{7}$ (korte tijd voordat de reliëfpanelen van Binnenhof 7 werden aangebracht), en in de zogenaamde 'Tempelkamer' die in 1928 onderdeel werd van de vaste tentoonstelling van het Koloniaal Museum, dat inmiddels naar Amsterdam was verhuisd (afb. 7). Het Prambanan motief, in meerdere variaties, hoorde daarbij, evenals kala-makara nisomlijstingen en Boeddhabeelden. ${ }^{8}$

\section{Nederlands-Indisch erfgoed}

Opvallend is, dat referenties aan Nederlands-Indië in Haagse architectuur vaak te vinden zijn in relatief kwetsbare onderdelen, zoals glas-in-lood.

Afb 7

De 'Tempelkamer', Koloniaal Museum, rond 1928. Foto: Tropenmuseum, Amsterdam. Coll.nr. 60054918. Met dank aan Ingeborg Eggink.

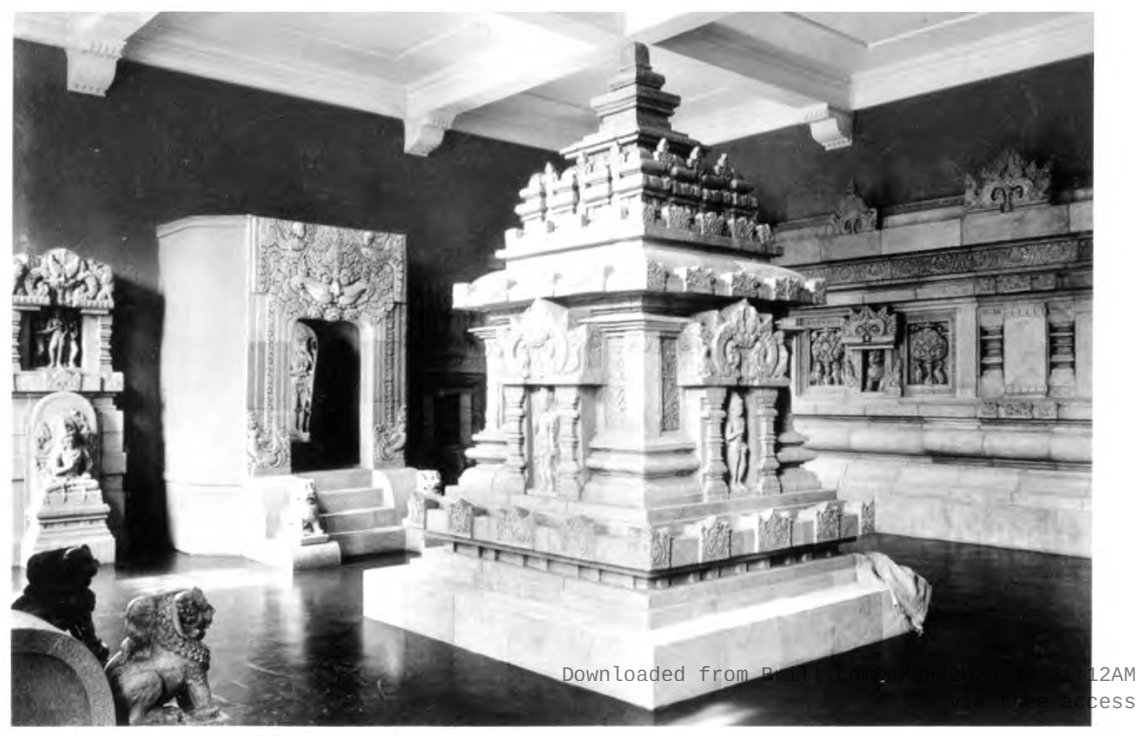


Hopelijk zal het Haagse project Sporen van Smaragd een stimulans geven om Nederlands-Indisch erfgoed uit de periode voor 1945 ook in andere regio's te inventariseren en documenteren.

Andréa Kroon is kunsthistoricus, werkzaam bij Kroon \& Wagtberg Hansen kunsthistorisch projectmanagement te Den Haag. Dit bureau is sinds 2010 belast met de uitvoering van het project Sporen van Smaragd.

Marijke J. Klokke is bijzonder hoogleraar Kunst en materiële cultuur van Zuiden Zuidoost-Azië aan de Universiteit Leiden en conservator Klassiek Zuid- en Zuidoost-Azië bij Rijksmuseum Volkenkunde te Leiden.

- Andréa Kroon en Audrey Wagtberg Hansen, Sporen van Smaragd. Haags-Indisch erfgoed, 1853-1945, Uitgeverij De Nieuwe Haagsche, Den Haag, 2013. [VOM-reeks] In 2012 verscheen van hun hand ook de eenmalige 'erfgoedglossy' Smaragd: Indisch erfgoed in Den Haag bij dezelfde uitgever.

\section{Literatuur}

Marieke Bloembergen, Colonial Spectacles: The Netherlands and the Dutch East Indies at the World Exhibitions, 1880-1931, chapter 4: 'The Topicality of Javanese Antiquity: Paris 1900', NuS Press, Singapore, 2006, pp. 164-219. (Ook online beschikbaar)

L.P.M.H. Michiels van Verduynen, Verslag der Centrale Commissie tot inrichting van de afdeelingen van Nederland en zijne koloniën en tot behartiging van de belangen der inzenders in die afdeelingen op de Wereldtentoonstelling te Parijs in 1900, Joh. Enschede en Zonen, Haarlem, 1902.

E.A. von Saher, De versierende kunsten in Nederlandsch Oost Indië: eenige Hindoe monumenten op Midden-Java, De Erven F. Bohn, Haarlem, 1900.

H. van der Wusten, M.C. Deurloo, S. de Vos, Indische buurten in Nederlandse steden, Universiteit van Amsterdam, Afdeling Geografie, Planologie en Internationale Ontwikkelingsstudies, 2007. (Online raadpleegbaar: http://mapinfoserver.fmg.uva.nV/ indischebuurten.html)

\section{Noten}

1 De beschrijving van Nederlands-Indië als 'gordel van smaragd' is ontleend aan Multatuli's Max Havelaar (1860). De Universiteit van Amsterdam verrichtte onderzoek naar Indische naamgeving van wijken, zie Van der Wusten et al. 2007.

2 Zie: www.sporenvansmaragd.nl. Het project werd in 2010 gestart door de afdeling Monumentenzorg van de Gemeente Den Haag.

3 Een van de eerste bewoners was Jhr. Willem Eduard van der Does de Bije (geb. Laboean, Deli, 1878-1955). Mogelijk heeft hij het raam laten aanbrengen.

4 Het beeld werd in 1978 aan Indonesië teruggegeven, waar het nu in de vaste opstelling van het Nationaal Museum in Jakarta is te zien.

5 Dit gebeurde voor het eerst op grote schaal op deze wereldtentoonstelling, zie Marieke Bloembergen 2006.

6 Michiels van Verduynen 1902: 202

7 http://nl.wikipedia.org/wiki/Koloniaal_Museum\#Vroegere_tentoonstellingen_ .28selectie.29 (laatst bezocht 15 mei 2013).

8 Von Saher 1900: 42, pl. V en XV. 